\title{
Prevention Strategies for Cardioembolic Stroke: Present and Future Perspectives
}

\author{
Giacomo Giacalone* ${ }^{* 1}$, Mohammed Abballa Abbas ${ }^{1,2}$ and Francesco Corea*,1,3 \\ ${ }^{1}$ Department of Neurology, Institute of Experimental Neurology (INSPE), IRCCS San Raffaele, Milano, Italy \\ ${ }^{2}$ Department Neurology, Sohag University Hospital, Sohag, Egypt \\ ${ }^{3}$ Unità Gravi Cerebrolesioni Acquisite (UGCA) Ospedale San Giovanni Battista, Foligno, Italy
}

\begin{abstract}
Atrial fibrillation (AF) is the most common cause of cardioembolism. An update on secondary prevention strategies, used to protect patients from the risk of stroke in many common cardiac conditions, is presented in the paper. The main line of actions of stroke prevention in cardioembolism is mostly connected with antithrombotic drugs, but also other, more invasive, techniques are quickly emerging. Also the classic pharmacological prevention with coumarins may soon be overcome by new generation anticoagulants. Is an aggressive treatment of Patent Foramen Ovale (PFO) always recommended? One of the main challenges of the future years will be to understand competitiveness between old and new preventive strategies.
\end{abstract}

Keywords: Cardioembolic stroke, risk factors, secondary prevention, antithrombotic drugs, atrial fibrillation, PFO.

\section{INTRODUCTION}

Cardioembolism accounts for about $20 \%$ of all ischemic strokes. Cardioembolic strokes are usually severe, prone to early recurrence and to hemorrhagic transformation. Also long -term recurrence and mortality are higher, probably due to the underlying pathogenetic mechanism. Clinical features may help to suspect a cardioembolic source, but usually have low sensitivity: these could be, sudden onset to maximal deficit, quick regression of symptoms, simultaneous or sequential strokes in different arterial territories, hemorrhagic transformation of an ischemic infarct, early recanalization of an occluded vessel. The confirmation of the cardiac origin or its discovery is based on cardiac functional and imaging techniques such as electrocardiogram, Holter monitoring, echocardiography. Various cardiac conditions have been clearly associated with an increase in the risk of ischemic stroke (Table 1). Because certain stroke risk factors, like hypertension, may also be determinants of cardiac disease, some cardiac conditions may be viewed as intervening events in the causal chain for stroke. Cardiac factors that independently increase the risk of stroke include AF, valvular heart disease, myocardial infarction, coronary artery disease, congestive heart failure [1,2]. Improved cardiac imaging has led to increased detection of potential predisposing conditions, such as patent foramen ovale (PFO), atrial septal aneurysms, aortic arch atherosclerotic disease, mitral anular calcification, spontaneous left atrial appendage echo contrast and valvular strands (thin filamentous material). Considerable advancements in relation to some cardioembolic conditions have occurred in recent years, especially in atrial

*Address correspondence to these authors at the GG \& FC: Department Neurology, INSPE; IRCCS San Raffaele, Via Olgettina, 48, 20132 Milano, Italia; Tel: +390226432813; Fax: +390226432951;

E-mail: corea.francesco@hsr.it; giacomo.giacalone@hsr.it fibrillation (AF), several evidence-based treatment strategies have emerged and novel therapeutic options will be available for the future. For other cardioembolic disorders there are still partial knowledge and conflicting opinions that limit the establishment of defined guidelines. This chapter provides an overview of the current state of knowledge for the major cardioembolic stroke risk factors and the strategies of primary and secondary prevention with particular interest to future therapeutical perspectives.

Table 1. Cardiac Risk Factors for Ischemic Stroke

\begin{tabular}{|c|c|}
\hline DEFINITE & POSSIBLE/PROBABLE \\
\hline \hline Atrial & Atrial \\
\hline Atrial Fibrillation & Patent foramen ovale \\
\hline Substained atrial flutter & Atrial septal aneurysm \\
\hline Sick sinus syndrome & Atrial or ventricular septal defects \\
\hline Atrial mixoma & Spontaneous echocontrast in left \\
atrial appendage
\end{tabular}




\section{ATRIAL FIBRILLATION (AF)}

Atrial Fibrillation is the most important cause of cardioembolic stroke. In Western countries AF is mainly associated with hypertensive and ischemic heart disease, but it can also occur in absence of any cardiac pathology (lone AF), while rheumatic mitral valve disease seems to be now very rare in industrialized areas. For this reason the following paragraphs relates only to non-valvular AF. The overall prevalence is approximately $1 \%$, but the prevalence among those older than 65 years is close to $6 \%$. Therefore, the attributable risk of stroke due to AF increases significantly with age, approaching the risk of hypertension among patients 80 to 89 years old. Approximately, $16 \%$ (11\% to $29 \%$ ) of all ischemic strokes are associated with AF [3], and among patients over 70 years old with ischemic stroke, more than one-third suffer from AF [1]. AF increases the relative risk of ischemic stroke about five-fold, roughly $1 \%$ to $5 \%$ per year for elderly people [3]. Loss of atrial contraction in AF leads to blood stasis, particularly, in the left atrial appendage which is a known pro-thrombotic condition.

\section{Standards in Cardioembolism Prevention}

Prevention of systemic embolism is achieved by means of restoration and control of sinus rhythm or with permanent anti-thrombotic treatment. Concerning the selection of the most appropriate antithrombotic regimen, clinical trials demonstrated that anticoagulation is more effective than aspirin. Five trials of primary prevention (AFASAK, SPAF I, BAATAF, CAFA, SPINAF) comparing warfarin vs. placebo found a relative risk reduction of $2.5 \%$ to $4.7 \%$ per year for ischemic stroke and absolute stroke rate reduction of $33 \%$ to $86 \%$ [3]: a recent meta-analysis of anti-thrombotic therapies for primary and secondary prevention of stroke in AF by Hart and collegues [4] confirmed the relative reduction in stroke risk with warfarin compared to placebo $(64 \%$; $95 \% \mathrm{CI}$ $49 \%$ to $74 \%$ ). The meta-analysis also showed a lower reduction in the relative risk of stroke when using antiplatelet therapy (8 trials, 4876 participants): $22 \%$ (95\%CI $6 \%$ to $35 \%$ ) [4]. Comparing directly warfarin with anti-platelet drugs, alone or in combination (e.g. aspirin plus clopidogrel in the ACTIVE W trial), the anticoagulation therapy reduced the relative risk of stroke of $39 \%$ (95\% CI $22 \%$ to $52 \%$; 12 trials, 12963 patients) [4]. Therefore the meta-analysis by Hart and colleagues validates that warfarin is more efficacious than aspirin in stroke risk reduction in primary and secondary prevention studies. The combination of warfarin plus antiplatelet drugs was tested versus warfarin alone in a metaanalysis of ten randomized trials by Dentali and collegues [5], but it didn't show an additive beneficial effect, while the risk of bleeding was increased in patients receiving the the combination therapy $(1.43 ; 95 \% \mathrm{CI} 1.00$ to 1.25$)$. Only the study NASPEAF [6] (National Study for Primary Prevention of Embolism in Non-rheumatic Atrial Fibrillation) reported a reduction in vascular events in the group of the combination of triflusal and acenocoumarol compared with warfarin alone (hazard ratio 0.33 ; 95\% CI 0.12-0.91).

The beneficial effect of warfarin in stroke risk prevention must be balanced with the risk of hemorrhage complications. The absolute risk of hemorrhage in patients with AF on warfarin calculated from randomized clinical trials averaged $2 \%$ per year, one quarter of which $(0.3 \%$ to $0.6 \%)$ were intracranial haemorrhage $[7,8]$. The risk of intra-cranial hemorrhage was doubled with warfarin compared with aspirin, although the increase in absolute risk was small $(0.2 \%$ per year). In the BAFTA (Birmingham Atrial Fibrillation Treatment of the Aged study) [9], a randomized clinical trial of warfarin versus aspirin in the elderly (age $>75$ years), the risk of hemorrhage was similar in both treatment groups, raising concern of possible selection bias like restriction to patients with moderate risk of stroke.

\section{Risk Stratification for Patients with AF}

Assessment of thromboembolic risk in AF is essential to guide the use of anticoagulation or anti-platelet therapy. In a recent systematic review of risk factors for stroke in AF patients, four clinical features emerged as consistent predictors: prior TIA or stroke (RR 2.5, 95\% CI 1.8 to 3.5), increasing age (RR 1.5 per decade, $95 \%$ CI 1.3 to 1.7 ), history of hypertension (RR 2.0, 95\%CI 1.6 to 2.5) and diabetes mellitus (RR 1.7, 95\%CI 1.4 to 2.0) [10]. Several risk factors stratification schemes (CHADS2, SPAF, AFI1, Framingham, ACCP, ACC/AHA/ESC guidelines, NICE/Birmingham) [11] have already been published, but evident differences exist between them. The most popular and validated of these schemes is the CHADS2 [11] (see Table 2) which relies on the previous four clinical predictors plus congestive heart failure, making its use simple for everyday clinical practice. Other variables that could ameliorate the risk stratification have been investigated, but conflicting results have been reported. Among these, echocardiographic findings: a pooled analysis of three studies, BAATAF, SPINAF, and SPAF I, showed that moderate to severe left ventricular dysfunction, but not left atrial size, was an independent predictor of stroke [12]; Shively and collegues [13] noted increased stroke risk associated with decreased left atrial flow velocity $(<15$ $\mathrm{cm} / \mathrm{sec}$ ), ventricular dilatation, and decreased left atrial ejection fraction in patients with $\mathrm{AF}$ and atrial enlargement; In another study, spontaneous echo contrast was significantly associated with AF-related stroke [14]. Coronary artery disease and female gender are also less certain risk modifiers,

Table 2. CHADS2 Scheme

\begin{tabular}{|c|c|c|c|}
\hline RISK FACTORS & POINTS & TOTAL SCORE & RISK OF STROKE \\
\hline \hline Prior stroke or TIA & 2 & $3-6$ & High \\
\hline Age $>75$ years & 1 & & $18.9 \%$ per year \\
\hline Diabetes mellitus & 1 & $1-2$ & Intermediate \\
Arterial hypertension & 1 & & Low $1.2 \%-4 \%$ per year \\
\hline Congestive heart failure & 1 & 0 & per year \\
\hline
\end{tabular}


but the latter was included as risk factor in two stratification schemes (SPAF and Framingham) [11].

The decision to use anticoagulant or aspirin depends on risk stratification of patients with AF. Aspirin carries a lower bleeding risk and requires less medical monitoring than do anticoagulants, but has a lower stroke risk reduction effect. Recent published guidelines for the management of atrial fibrillation [15], in particular for stroke prevention, recommend the use of anticoagulation in patients with more than 1 moderate risk factors (age 75 years or older, hypertension, heart failure, ejection fraction below $35 \%$ or fractional shortening less than $25 \%$ and diabetes mellitus) (level of evidence A). Aspirin, 81-325 mg daily, is recommended as an alternative to vitamin $\mathrm{K}$ antagonists in low-risk patients or in those with contraindications to oral anticoagulation (level of evidence A). For patients with less validated risk factors or with only 1 risk factor it is reasonable to choose the antithrombotic therapy based upon an assessment of the risk of bleeding complications, ability to safely sustain adjusted chronic anticoagulation, and patient preferences (level of evidence A). The same criteria in selecting the antithrombotic therapy should be used irrespective of the pattern (i.e., paroxysmal, persistent, or permanent) of AF (level of evidence B).

\section{When to Start with Anticoagulation?}

The issue of when to initiate anticoagulation treatment in a patient with AF with stroke or TIA is extremely important on the light of the high risk of stroke recurrence in the first two weeks and of the high risk of haemorrhagic transformation of the cerebral infarct (Fig. 1). The recent meta-analysis by Paciaroni and collegues [16] and the update by Guedes and Ferro [17], addresses this issue evaluating 8 randomized trials comparing anticoagulants (unfractionated heparin or low-molecular-weight heparin or heparinoids) started in the first 48 hours with other treatments in patients with acute ischemic cardioembolic stroke. The results of the metaanalysis didn't show a significant reduction in recurrent ischemic stroke within 7 to 14 days with anticoagulation compared with other treatments $(3.0 \%$ versus $4.9 \%$. OR $0.68,95 \%$ CI 0.44 to $1.06, p=0.09$ ), while the symptomatic intracranial bleeding were increased with early anticoagulation therapy $(2.5 \%$ versus $0.7 \%$, OR $2.89,95 \%$ CI 1.19 to $7.01, \mathrm{p}=0.02)$. Death or disability at final follow up were similar in the two groups $(73.5 \%$ versus $73.8 \%$, OR 1.01 , $95 \%$ IC 0.82 to $1.24, \mathrm{p}=0.9$ ). The difference in death and disability was statistically significant in only one trial $(58.5 \%$ versus $74.1 \%$, OR $0.49,95 \%$ IC 0.26 to 0.93 ) [18] which was the only study with anticoagulation therapy started within 3 hours from stroke onset. The positive effect of early heparin could be ascribed, as suggested by several studies [19,20], also to its anti-inflammatory properties than to its antithrombotic ones. However additional clinical trials in the three-hour period are needed to confirm this finding. Current guidelines and usual practice recommend that anticoagulation should be started as soon as possible in patients with AF after brain imaging for a TIA and should be delayed in ischemic stroke, according to ischemic lesion extension, clinical severity and cardiologic comorbidity, stroke in favour of anti-platelet therapy $[1,21]$.

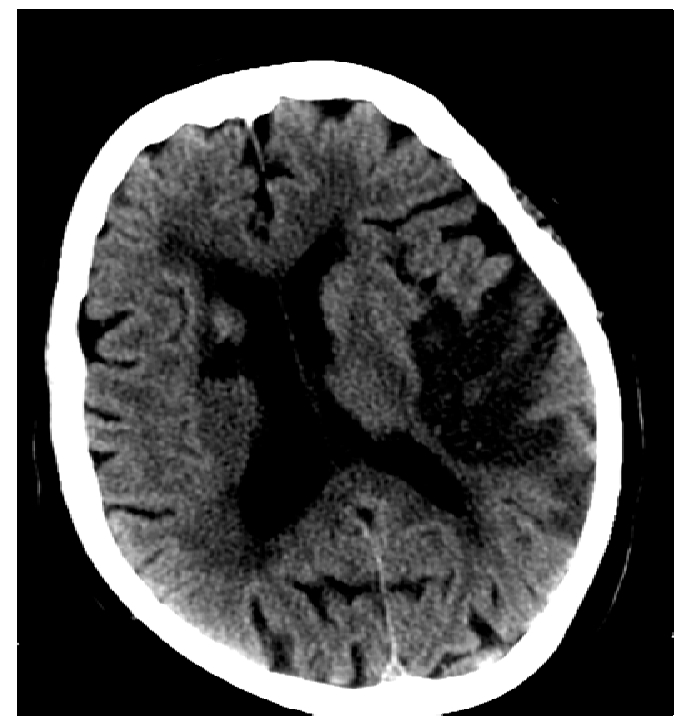

Fig. (1). Cardioembolic stroke: left hemispheric middle cerebral artery infarction with visible bleedings (petecchiae) and sulci effacement.

\section{Future Treatment Perspectives in AF}

Future strategies for stroke prevention in AF include i) fixed low-dose warfarin anticoagulation; ii) new oral anticoagulant drugs; iii) non-pharmacological approaches.

One meta-analysis reported that fixed low-dose warfarin compared with adjusted-dose warfarin was associated with more thromboembolic events without reducing the risk of bleeding complications [22]. New oral anticoagulant drugs are currently in development owing to the many limitations of vitamin $\mathrm{K}$ antagonists. There are two main types of these agents: direct thrombin inhibitors (DTIs) and oral factor Xa inhibitors (FXaI). The first DTI tested was ximelagatran, that showed in a phase III clinical trial a significant reduction in terms of prevention of stroke in AF compared to warfarin, but was then abandoned because of hepatotoxicity in a substantial number of patients [11]. Others DTIs like dabigatran and megalatran are currently under investigation. Dabigatran has been recently investigated in the RE-LY trial [23], which randomly assigned 18,113 patients who had atrial fibrillation to receive fixed doses of dabigatran $(110 \mathrm{mg}$ or $150 \mathrm{mg}$ twice daily) or adjusted-dose warfarin: the risk of stroke was reduced in patients receiving dabigatran at a dose of $150 \mathrm{mg}$ twice daily respect to warfarin (95\% CI $0.53-0.82, \mathrm{p}<0.001$ for superiority) and the risk of major bleedings was reduced in patients receiving $110 \mathrm{mg}$ of dabigatran twice daily respect to warfarin $(\mathrm{p}=0.003)$; the study also demonstrated the non-inferiority of the $110 \mathrm{mg}$ dose of dabigatran versus warfarin in stroke reduction and of the $150 \mathrm{mg}$ dose of dabigatran versus warfarin in major bleeding risk. The major advantage of dabigatran respect to warfarin is that it doesn't need dose adjustment and therefore it should be less prone to inadequate anticoagulation. The parenteral FXaI idraparinux has been compared to warfarin in the AMADEUS trial in patient with $\mathrm{AF}$, but clinically bleeding complications were significantly higher in the idraparinux group $(19.7 \%$ vs $11.3 \%, \mathrm{p}=0.007)$ and the drug achieved the criteria of noninferiority [24]. Other oral FXaI like rivaroxaban and apixaban are currently under investigation. Furthermore a new 
orally active, selective, reversible FXa inhibitor, DU-176b [N-(5-Chloropyridin-2-yl)-N-[(1S,2R,4S)-4-(N,Ndimethylcarbamoyl)-2-(5-methyl-4,5,6,7-tetrahydrothiazolo [5,4-c]pyridine-2carboxamido)cyclohexyl] ethanediamide p-toluenesulfonate monohydrate], is currently under investigation. In non-clinical studies [25, 26], DU-176b showed excellent potential as an antithrombotic agent. Non-clinical data indicate no evidence of liver function abnormalities in study animals exposed to DU-176b. In Japan, two early phase 2a, DU-176b, open-label, dose-escalation studies were conducted in a total of 56 subjects with nonvalvular AF. Subjects were treated for 6 to 10 weeks with total daily doses of $5 \mathrm{mg}$ to $120 \mathrm{mg}$ : the doses evaluated in this study were well tolerated, no major bleeding was reported. There was one clinically relevant non-major bleeding reported for each of the following DU-176b regimens: $30 \mathrm{mg}$ bid, $45 \mathrm{mg}$ bid, and $60 \mathrm{mg}$ bid [26]. There were no others observed clinically relevant liver function abnormalities. A phase 3 , randomized, double-blind, double-dummy, parallel-group, multi-center, multi-national study for evaluation of efficacy and safety of DU-176b versus warfarin in subjects with atrial fibrillation, ENGAGE AF-TIMI48 trial (Effective Anticoagulation with factor xA next Generation in Atrial Fibrillation) is currently ongoing: data from this study are expected for 2011.

The non-pharmacological approaches for stroke prevention can be divided in an electrophysiological approach like ablation techniques with the aim of restoring the sinus rhythm and a mechanical approach with the aim of preventing the formation of thrombus in left atrium appendage or to divert it from the cerebral circulation.

The electrophysiological approach is based on two types of ablation procedures, the "maze" procedure that involves complex lesioning of the left atrium and the pulmonary veins isolation [27]. In selected series the pulmonary veins isolation appears to prevent symptomatic $\mathrm{AF}$ in $80 \%$ to $90 \%$ at 1 year of follow-up $[1,27]$, but there are no data about the durability of this effect.

The rationale behind the mechanical approach is that the most of thrombi that then embolise originates from the left atrium appendage where there is an hypercoagulable state because of the blood stasis. Today, surgical excision of the left atrium appendage is routinely performed as an adjunct to cardiac surgery in those cases at high risk for left atrium appendage-related thromboembolism. The North American guidelines for management of patients with valvular heart disease recommend amputation of the left atrium appendage at the time of mitral valve surgery to reduce the risk of stroke [28]. Exclusion of the left atrium appendage can also be performed thoracoscopically under general anesthesia by applying a loop snare or by stapling the base of the left atrium appendage. Occlusion, as opposed to ligation or amputation, of the left atrium appendage can also be performed using three percutaneous-catheter-based systems: the Percutaneous Left Atrial Appendage Transcatheter Occlusion (PLAATO ${ }^{\circledR}$ ) system, the WATCHMAN ${ }^{\circledR}$ system and the AMPLATZER ${ }^{\circledR}$ [28]. The development of left atrium appendage occlusion systems provides a promising alternative to anticoagulation, specially for patients at high risk of AF-related stroke who cannot tolerate anticoagulation. However safety and effectiveness must be still verified by additional studies. In initial studies, complications requiring surgical exploration (e.g. device embolisation, pericardial tamponade, stroke, and death) occurred at higher than acceptable frequencies [28].

\section{PATENT FORAMEN OVALE (PFO)}

During the last decade, there has been an increasing emphasis on the role of patent foramen ovale (PFO) in the genesis of ischemic juvenile stroke. Several case control studies and a meta-analysis $[29,30]$ have shown that PFO was significantly associated with stroke in patients younger than 60 years of age, in particular in the subgroup of young patients with cryptogenic stroke. A recent case-control study by Handke and collegues [31] has shown that also in the age group of patients older than 55 years with cryptogenic stroke the prevalence of PFO was significantly greater than in patients with non-cryptogenic stroke with an odds ratio after the multivariate analysis of $3.00(95 \% \mathrm{CI}, 1.73$ to 5.23 ; $\mathrm{p}<0.001)$ [31]. The previous meta-analysis by Overell and collegues [29] didn't show a significant risk associated with PFO in patient older than 55 years with cryptogenic stroke based on three studies (only one of these studies had shown a significant risk in patients older than 55 years) [32]. In the study by Homma and collegues [33] in an exploratory analysis of patients with cryptogenic stroke from the PICSS study (PFO in Cryptogenic Stroke Study), the PFO significantly increased the risk of adverse events at two years of follow-up in patients older than 65 years but not in patients younger than 55 years $(\mathrm{p}=0.01$; hazard ratio $3.21 ; 95 \% \mathrm{CI}, 1.33$ to 7.75). The controversial findings of these studies have raised concern in commentaries about the selection of the study populations and further studies are needed to investigate the issue. Cerebral paradoxical embolism is usually a presumed diagnosis, because direct evidence, such as a thrombus lodged in the PFO shown on transesophageal echocardiography or the discovery of a deep venous thrombosis, is commonly lacking. Despite these ongoing controversies, it is reasonable to incriminate a cerebral paradoxical embolism in young patients with no other identified cause of stroke than PFO.

The optimal treatment of these patients remains a matter debate, mainly because of a lack of controlled clinical trials. There are four therapeutic options: antiplatelets drugs, anticoagulants, closure of PFO by transcatheterization or closure of PFO by surgery. The only two studies [34,35] of secondary prevention of stroke in patients with PFO show that the risk of recurrent stroke is relatively low, about $1 \%$ per year, in patients treated with aspirin or short-term anticoagulation. In the Lausanne Study [34] and the French Study Group [35], the annual rate of TIA was 3.8\% and 3.4\%, of stroke alone, $1.9 \% 1.2 \%$, respectively.

At present, there is little information on the risk of stroke recurrence in those with PFO associated with an atrial septal aneurysm (ASA) compared to PFO alone, and some have suggested that PFO with an ASA, or large PFOs with rightto-left shunting, have more stroke risk [36, 37]. Several factors have been suggested to increase the risk for stroke or recurrent stroke in patients with PFO: these includes a younger age [29], the association with atrial septal aneurysm (ASA) [29, 38], the presence of a right-to-left shunt at rest, the size of the PFO $[39,40]$, the association with thrombophilic conditions [41]. Despite a meta-analysis and other studies have reported a strong increase in stroke risk and stroke recurrence in patients with both PFO and ASA com- 
pared with PFO alone, specially in cryptogenic stroke, other studies failed to confirm this association [32, 33]. Also for the other presumed risk factors further evaluations are needed because of controversial findings. On these grounds, Nendaz et al. [42] created a decision analysis model for the clinician. This model indicates that for a stroke risk recurrence of $1.4 \%$ to $7 \%$ per year, there was more benefit from surgical closure of the PFO than from any other treatment. When the risk is from $0.8 \%$ to $1.4 \%$ per year, anticoagulants and antiplatelets are better than placebo, while when it is $<0.8 \%$ per year, neither medical nor surgical treatment is indicated. Further studies are planned to determine the stroke risk in subgroups of PFO patients using transcranial Doppler ultrasound with the microbubble technique, which may be more accurate than transesophageal echocardiography [43]. At present, treatment is limited to the application of empirical clinical criteria. Useful clarifications for the best approach in the long- term management of PFO with TIA or stroke could come from the epidemiological data of the Forame Ovale Registro Italiano (FORI), a multicentric registry based in Perugia, established in 2003.

Surgical closure of PFO without stroke recurrence has been reported [44, 45], but others have not been so fortunate [46]. A minimally invasive alternative to surgery consists in transcatheter closure of the PFO. The procedure involves the percutaneous implantation of a device to occlude the interatrial septum $\left(\right.$ CardioSEAL $^{\circledR}$ and Amplatzer ${ }^{\circledR}$, approved by FDA). The reported complications following PFO closure are infrequent and are associated with low morbidity and mortality. Adverse events includes brief atrial fibrillation $(0.8 \%)$, device dislodgement $(0.4 \%)$, device arm fracture (3.6\%) and surgical explanation (0.8\%) [47]. However longterm consequences of PFO closure are unknown. A review of 12 uncontrolled case series of more than 100 patients documented a rate of stroke recurrence during the first year after transcatheter PFO closure between 0 and 5\% [46]; the percentages during the other years of follow-up varied considerably between the different studies. Current data suggest that transcatheter closure is at least effective as medical treatment, but further studies are necessary to investigate this issue.
The use of coumarins is risky in young patients with a long life expectancy because of the major bleeding risk, estimated at $1.5 \%$ to $11 \%$ per year [45]. The ACCP guidelines [48] recommend anti-platelet therapy in patients with ischemic stroke and PFO; anticoagulants are recommended when a deep venous thrombosis (DVT) is demonstrated by ultrasound investigation or by venography, when there is association with an underlying hypercoagulable state and before closing the PFO in those with a presumed higher risk of stroke recurrence. PFO closure might be considered for patients with recurrent cryptogenic ischemic strokes, despite antithrombotic therapy or after the first event in patients with high-risk conditions such as presence of DVT, hypercoagulable state, characteristic of PFO documented by transesophageal echocardiography. In practice, and until results of future studies focusing on risk stratification are reported, the following criteria could be applied to decide secondary prevention therapy in patients with stroke and PFO (Table 3): (1) more than one cerebrovascular event clinically or on MRI scan, (2) evidence of DVT, (3) demonstration of an hypercoagulable state, (4) significant right-to-left shunting through the PFO documented by echocardiography or Doppler, (5) PFO associated with ASA and (6) a history of Valsalva's manoeuvre just before the clinical event.

\section{PROSTHETIC HEART VALVES (PHV)}

In the last decades the replacement of heart valves constantly increased: considering only aortic valve disease, more than 200,000 replacements are currently performed annually worldwide [49].

In patients with prosthetic heart valves, thromboembolic events occur at a rate of 7 to $34 \%$ per year without anticoagulant therapy and at a rate of 1 to $5 \%$ per year with oral anticoagulation [50]. Two types of PHV are used: bioprosthetic valves and mechanical valves. Both mechanical and bioprosthetic valves are at increased risk of stroke, which however is confined in the latter to the first months after implantation, while it is long-lasting in the former; the last decade have seen a dramatic reduction in the use of mechanical valves (aortic valve: $21 \%$ mechanical vs. $79 \%$ of

Table 3. Secondary Prevention in Patients with PFO-Associated Stroke: Risk Stratification-Based Recommendations

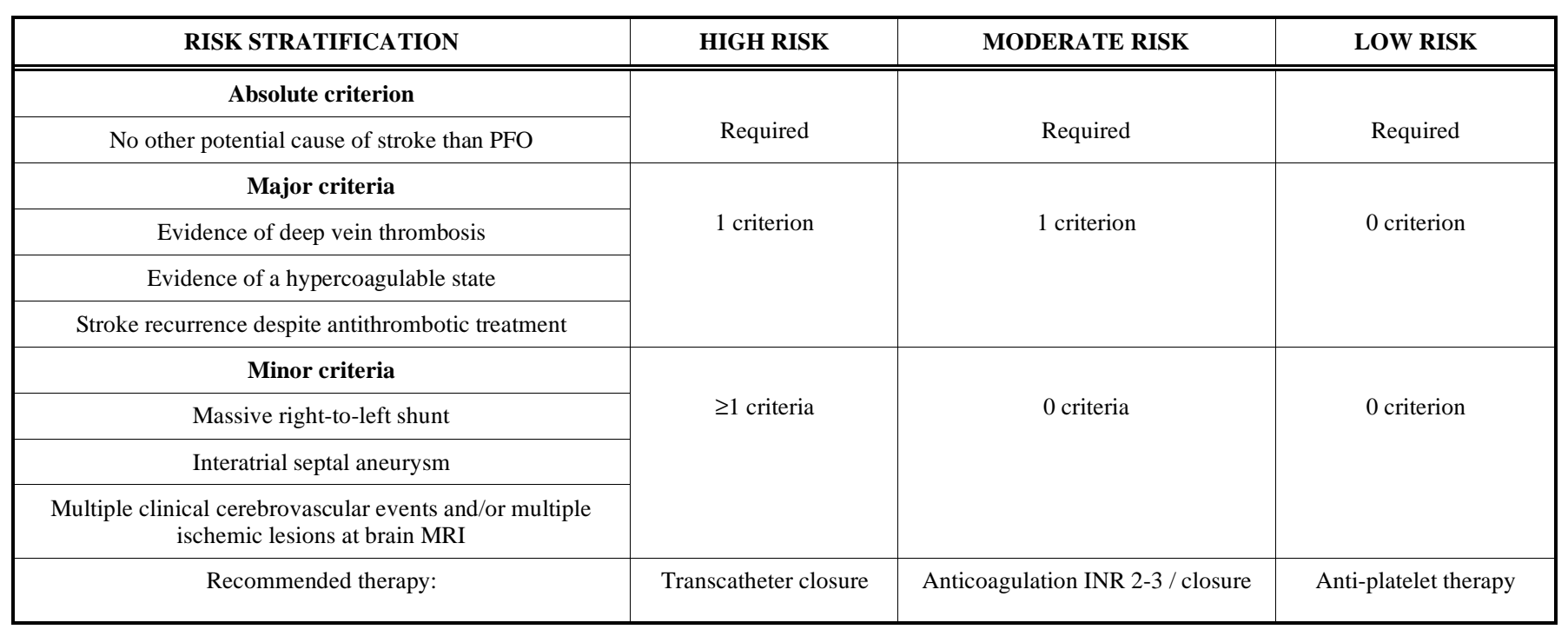


bioprosthetic [49]; mitral valve: 55\% repair techniques, $28 \%$ mechanical, 17\% bioprosthetic [51]) mostly because of the need of a life-long anticoagulant therapy. Thromboembolic risk associated with PHV is also related to the site of valve replacement, being higher for mitral valve than for aortic valve, and to the kind of mechanical valve used, being lower for the bileaflet ones than for monoleaflet and caged ball ones. The presence of other risk factors, such as AF, left ventricular dysfunction, spontaneous echocardiographic contrast in the left atrium and increasing age obviously also increase the chance of embolism [52]. Stroke may occur from either inadequate anticoagulation or because thrombogenic factors are inadequately suppressed despite adequate anticoagulation therapy. The precise pathophysiology of thromboembolism in patients with PHV remains uncertain. Increased shear rates at the valve surfaces may activate platelets, generating platelet-derived microparticles, which could have potent procoagulant activity. Furthermore, the presence of microemboli, frequently encountered in these patients, may result from harmless gaseous bubbles (cavitation) [53].

As yet, no prospective randomized studies have been done in patients with mechanical valves to assess the efficacy of antithrombotic therapy. In a meta-analysis comprising more than 53,000 patient-years, the major embolism rate without antithrombotic therapy was $4.0 \%$ per year, reduced to $2.2 \%$ year with antiplatelets and to $1.0 \%$ per year with anticoagulants [50]. Current guidelines of the ACCP [48] recommend the use of anticoagulation with an INR range of 2 to 3 for bileaflet mechanical aortic valves, with an INR range of 2,5 to 3,5 for mechanical mitral valves and for monoleaflet valves; in case of stroke during anticoagulation or if there are concomitant vascular risk factors, it is recommended the use of anti-platelet therapy like aspirin 75$100 \mathrm{mg}$ per day in addition to anticoagulation (INR range 2,5 to 3,5); in patients with bioprosthetic valves it is recommended anticoagulant therapy for the first 3 months after implantation followed by anti-platelet therapy.

\section{ACUTE MYOCARDIAL INFARCTION (AMI)}

About $1 \%$ to $5 \%$ of patients with AMI have an ischemic stroke, most of them cardioembolic, occurring within two to four weeks. Stroke occurred especially in those with anterior AMI, in whom the risk of ischemic stroke raises to $12 \%$ [3], and in patients with large anterior infarcts [54]. In the first month after AMI, incidence rates were $1 \%$ to $3.2 \%$, and $\mathrm{AF}$ and ST segment elevation were significant predictors [55]. Left ventricular thrombi, in older patients with large transmural infarcts, especially those with congestive heart failure, have an increased risk of stroke. Transesophageal echocardiography is needed to diagnose ventricular thrombosis, but it should be performed at least 24 hours after AMI, because these develop usually 1 to 10 days after AMI. Approximately $15 \%$ of AMI patients with recognized LVT will suffer stroke [3]. No randomized trials have been carried out comparing aspirin to anticoagulants to prevent stroke following AMI, though anticoagulants alone were shown effective in preventing recurrent AMI (INR 2.8 to 4.8) and stroke in the Anticoagulants in Secondary Prevention of Events Coronary Thrombosis (ASPECT) trial. No comparison with aspirin was ever made [56]. Early randomized trials showed that heparin followed by low-intensity oral anticoagulation (INR 1.6 to 2.5 ) reduced stroke by about $70 \%$ in the weeks follow- ing AMI [3]. Being stroke rate three months after AMI so low, long-term anticoagulation beyond three months is not justified unless other major cardiac embolic risk factors, such as mural thrombosis, are present.

\section{OTHER CARDIAC ARRHYTMIAS}

Data concerning Atrial Flutter and Atrial FibrillationFlutter are scarce, and the exact risk of stroke associated with these conditions is unknown. Nevertheless, in a recent small study in patients without history of brain ischemia, the annual risk of stroke was only $1.6 \%$ [57]. In a recent prospective study of sick sinus syndrome (SSS), previous cerebral ischemic events, an age $>65$ years, left atrial spontaneous echocardiographic contrast and depressed atrial ejection force were independent risk factors for stroke $[59,60]$. Those with $\mathrm{AF}$ showed a thromboembolic rate of $5 \%$ per year, compared to $3.5 \%$ per year in those without AF [3], though a more recent study reported stroke rate of $10 \%$ per year [58,59]. Dual-chamber cardiac pacemakers reduced both the occurrence of AF as well as thromboembolism in comparison to ventricular pacing. For secondary prevention in patients with well established SSS, anticoagulation should be considered, irrespective of the presence or absence AF [3]. The value of antiplatelets, the optimal intensity anticoagulation, and the safety chronic anticoagulation in elderly patients still remains uncertain.

\section{CONCLUSIONS}

During the last decades many efforts have been focused on AF, by far the commonest cause of cardioembolic stroke, to establish evidence-based recommendations for primary and secondary stroke prevention: the use of long-term anticoagulation (INR 2-3) substantially reduced stroke recurrence risk and is now clearly established as a powerful treatment strategy; furthermore individualized treatment decisions based on risk factor stratification schemes like CHADS2, are now widely accepted and available to simply guide the clinician in the optimal anti-thrombotic strategy. On the other hand, however, there is still partial knowledge and conflicting results for other cardiac disorders like PFO, for which, although the real pathogenetic weight is still unknown, several aggressive treatment strategies, like implantation of cardiac devices for life-time, are quickly spreading in current clinical practice. Can the risk of unpredictable potential long-term complications be balanced by the treatment of a still partial known pathogenetic factor? Novel large, controlled clinical trials and the creation of large, diseases registries are expected to answer to these important questions. But above all, the hope for the next decade is directed to the development of new generation anticoagulants which could revolutionize the cardioembolic prophylaxis.
ABBREVIATIONS
$\mathrm{AF}$
$=$ Atrial fibrillation
PFO
$=$ Patent foramen ovale
MRI
$=$ magnetic resonance imaging
DTIs $=$ direct thrombin inhibitors
FXaI $=$ factor Xa inhibitors
ASA $=$ atrial septal aneurysm 


$$
\begin{array}{ll}
\text { DVT } & =\text { deep venous thrombosis } \\
\text { PHV } & =\text { prosthetic heart valves } \\
\text { INR } & =\text { International Normalized Ratio } \\
\text { AMI } & =\text { Acute myocardial infarction } \\
\text { SSS } & =\text { sick sinus syndrome }
\end{array}
$$$$
\text { ACCP }=\text { American College of Chest Physicians }
$$$$
\text { ACC/AHA } /=\text { American College of Cardiology/American }
$$

\begin{tabular}{|c|c|c|}
\hline PAF I & $=$ & $\begin{array}{l}\text { The Stroke Prevention in Atrial Fibrillation } \\
\text { Study }\end{array}$ \\
\hline 3AATAF & $=$ & $\begin{array}{l}\text { Boston Area Anticoagulation Trial for Atrial } \\
\text { Fibrillation }\end{array}$ \\
\hline CAFA & $=$ & Canadian Atrial Fibrillation Anticoagulation \\
\hline SPINAF & $=$ & $\begin{array}{l}\text { Silent Cerebral Infarction in Patients With } \\
\text { Nonrheumatic Atrial Fibrillation }\end{array}$ \\
\hline CTIVE W & $=$ & $\begin{array}{l}\text { Atrial Fibrillation Clopidogrel Trial with } \\
\text { Irbesartan for Prevention of Vascular Events }\end{array}$ \\
\hline NASPEAF & $=$ & $\begin{array}{l}\text { National Study for Primary Prevention of } \\
\text { Embolism in Non-rheumatic Atrial Fibrilla- } \\
\text { tion }\end{array}$ \\
\hline BAFTA & $=$ & $\begin{array}{l}\text { Birmingham Atrial Fibrillation Treatment of } \\
\text { the Aged study }\end{array}$ \\
\hline CHADS2 & $=$ & $\begin{array}{l}\text { Congestive heart failure, Hypertension, Age, } \\
\text { Diabetes mellitus, Stroke }\end{array}$ \\
\hline RE-LY & $=$ & $\begin{array}{l}\text { Randomized Evaluation of Long-term anti- } \\
\text { coagulation therapY }\end{array}$ \\
\hline ENGAGE & $=$ & $\begin{array}{l}\text { Effective aNticoaGulation with factor } \mathrm{xA} \\
\text { next GEneration in Atrial Fibrillation }\end{array}$ \\
\hline FORI & $=$ & Forame Ovale Registro Italiano \\
\hline ASPECT & $=$ & $\begin{array}{l}\text { Anticoagulants in Secondary Prevention of } \\
\text { Events Coronary Thrombosis }\end{array}$ \\
\hline $\begin{array}{l}\text { PLAATO }^{\circledR} . \\
\text { system }\end{array}$ & $=$ & $\begin{array}{l}\text { Percutaneous Left Atrial Appendage } \\
\text { Transcatheter Occlusion }\end{array}$ \\
\hline
\end{tabular}$$
\text { ESC Heart Association/ European Society of }
$$
Cardiology

AFASAK $=$ Atrial Fibrillation, Aspirin, and Anticoagulant Therapy Study

\section{REFERENCES}

[1] Weir NU. An update on cardioembolic stroke. Postgrad Med J 2008; 84: 133-42.

[2] Ferro JM. Cardioembolic stroke: an update. Lancet Neurol 2003; 2: $177-88$.

[3] Hart RG, Albers G, Koudstaal PJ. Cardioembolic stroke. Cerebrovascular Disease, Maiden, Mass: Blackwell, 1998; vol. 2: pp. 1392-429.

[4] Hart RG, Pearce LA, Aguilar MI. Meta-analysis: antithrombotic therapy to prevent stroke in patients who have nonvalvular atrial fibrillation. Ann Intern Med 2007; 146: 857-67.

[5] Dentali F, Douketis JD, Lim W, Crowther M. Combined aspirinoral anticoagulant therapy compared with oral anticoagulant therapy alone among patients at risk for cardiovascular disease: a metaanalysis of randomized trials. Arch Int Med 2007; 167: 117-24.

[6] Perez-Gomez F, Alegria E, Berjon J, et al. Comparative effects of antiplatelet, anticoagulant, or combined therapy in patients with valvular and nonvalvular atrial fibrillation: a randomized multicenter study. J Am Coll Cardiol 2004; 44: 1557-66.
Hylek EM, Evans-Molina C, Shea C, Henault LE, Regan S. Major hemorrhage and tolerability of warfarin in the first year of therapy among elderly patients with atrial fibrillation. Circulation 2007; 115: 2689-96.

[8] Hart RG, Tonarelli SB, Pearce LA. Avoiding central nervous system bleeding during antithrombotic therapy: recent data and ideas. Stroke 2005; 36: 1588-93.

[9] Mant J, Hobbs FD, Fletcher K, et al. Warfarin versus aspirin for stroke prevention in an elderly community population with atrial fibrillation (the Birmingham Atrial Fibrillation Treatment of the Aged Study, BAFTA): a randomized controlled trial. Lancet 2007; 370: 493-503.

[10] Stroke Risk in Atrial Fibrillation Working Group. Independent predictors of stroke in patients with atrial fibrillation: a systematic review. Neurology 2007; 69: 546-54.

[11] Lip GY, Lim HS. Atrial fibrillation and stroke prevention. Lance Neurol 2007; 6: 981-93.

[12] The Stroke Prevention in Atrial Fibrillation Investigators Committee on Echocardiography. Transesophageal echocardiographic correlates of thromboembolism in highrisk patients with nonvalvular atrial fibrillation. Ann Intern Med 1998: 639-47.

[13] Shively BK GE, Crawford MH. . Regional left atrial stasis during atrial fibrillation and flutter. J Am Coll Cardiol 1996: 1722-9.

[14] Chimowitz MI, DeGeorgia MA, Poole RM, Hepner A, Armstrong WM. Left atrial spontaneous echo contrast highly associated with previous stroke in patients with atrial fibrillation or mitral stenosis. Stroke 1993: 24: 1015-9.

[15] Fuster V, Ryden LE, Cannom DS, et al. ACC/AHA/ESC Guidelines for the Management of Patients with Atrial Fibrillation: a report of the American College of Cardiology/American Heart Association Task Force on Practice Guidelines and the European Society of Cardiology Committee for Practice Guidelines (Writing Committee to Revise the 2001 Guidelines for the Management of Patients With Atrial Fibrillation): developed in collaboration with the European Heart Rhythm Association and the Heart Rhythm Society. Circulation 2006; 114: e257-354.

[16] Paciaroni M, Agnelli G, Micheli S, Caso V. Efficacy and safety of anticoagulant treatment in acute cardioembolic stroke: a metaanalysis of randomized controlled trials. Stroke 2007; 38: 423-30.

[17] Guedes LC, Ferro JM. A systematic review of immediate anticoagulation for ischemic stroke of presumed cardioembolic origin Stroke 2008; 39: e81-2; author reply e3.

[18] Camerlingo M, Salvi P, Belloni G, Gamba T, Cesana BM, Mamoli A. Intravenous heparin started within the first 3 hours after onset of symptoms as a treatment for acute nonlacunar hemispheric cerebral infarctions. Stroke 2005; 36: 2415-20.

[19] Vignoli A, Marchetti M, Balducci D, Barbui T, Falanga A. Differential effect of the low-molecular-weight heparin, dalteparin, and unfractionated heparin on microvascular endothelial cell hemostatic properties. Haematologica 2006; 91: 207-14.

[20] Cervera A, Justicia C, Reverter JC, Planas AM, Chamorro A. Steady plasma concentration of unfractionated heparin reduces infarct volume and prevents inflammatory damage after transient focal cerebral ischemia in the rat. J Neurosci Res 2004; 77: 565-72.

[21] Gensini GF, Ed. The SPREAD Collaboration. Italian Guidelines on Stroke, VI ed. Milan, Italy: Hyperphar Group-Catel Publishers 2007.

[22] Perret-Guillaume C, Wahl DG. Low-dose warfarin in atrial fibrillation leads to more thromboembolic events without reducing major bleeding when compared to adjusted-dose - a meta-analysis. Thromb Haemost 2004; 91: 394-402.

[23] Connolly SJ, Ezekowitz MD, Yusuf S, et al. Dabigatran versus warfarin in patients with atrial fibrillation. N Engl J Med 2009, 361: 1139-51.

[24] Bousser MG, Bouthier J, Buller HR, et al. Comparison of idraparinux with vitamin $\mathrm{K}$ antagonists for prevention of thromboembolism in patients with atrial fibrillation: a randomized, openlabel, non-inferiority trial. Lancet 2008; 371: 315-21.

[25] Furugohri T, Isobe K, Honda Y, et al. DU-176b, a potent and orally active factor Xa inhibitor: in vitro and in vivo pharmacological profiles. J Thromb Haemost 2008; 6: 1542-9.

[26] Hylek E. DU-176b, an oral, direct Factor Xa antagonist. Curr Opin Investig Drugs 2007; 8: 778-83.

[27] Dong J, Calkins H. Technology insight: catheter ablation of the pulmonary veins in the treatment of atrial fibrillation. Nat Clin Pract Cardiovasc Med 2005; 2: 159-66. 
[28] Syed TM, Halperin JL. Left atrial appendage closure for stroke prevention in atrial fibrillation: state of the art and current challenges. Nat Clin Pract 2007; 4: 428-35.

[29] Overell JR, Bone I, Lees KR. Interatrial septal abnormalities and stroke: a meta-analysis of case-control studies. Neurology 2000; 55: 1172-9.

[30] De Belder MA TL, Leech G, Camm AJ. Risk of patent foramen ovale for thromboembolic events in all age groups. Am J Cardiol 1992, 69(16):1316-20.

[31] Handke M, Harloff A, Olschewski M, Hetzel A, Geibel A. Patent foramen ovale and cryptogenic stroke in older patients. N Engl J Med 2007; 357: 2262-8.

[32] Di Tullio MR, Sacco RL, Sciacca RR, Jin Z, Homma S. Patent foramen ovale and the risk of ischemic stroke in a multiethnic population. J Am Coll Cardiol 2007; 49: 797-802.

[33] Homma S, DiTullio MR, Sacco RL, Sciacca RR, Mohr JP. Age as a determinant of adverse events in medically treated cryptogenic stroke patients with patent foramen ovale. Stroke 2004; 35: 2145-9.

[34] Bogousslavsky J, Garazi S, Jeanrenaud X, Aebischer N, van Melle G. Stroke recurrence in patients with patent foramen ovale: the Lausanne Study, Lausanne Stroke with Paradoxal embolism Study Group. Neurology 1996: 46(5): 1301-5.

[35] Mas JL ZM. Recurrent cerebrovascular events in patients with patent foramen ovale, atrial septal aneurysm or both and cryptogenic stroke transient ischemic attack: French Study Group on Patent Foramen Ovale an Atrial Septal Aneurysm. Am Heart J 1995; 130(5): 1083-8.

[36] Homma S, Di Tullio MR, Sacco RL, Mihalatos D, Li Mandri G, Mohr JP. Characteristics of patent foramen ovale associated with cryptogenic stroke. A biplane transesophageal echocardiographic study. Stroke 1994; 25: 582-6

[37] Steiner MM, Di Tullio MR, Rundek T, et al. Patent foramen ovale size and embolic brain imaging findings among patients with ischemic stroke. Stroke 1998; 29: 944-8.

[38] Mas JL, Arquizan C, Lamy C, et al. Recurrent cerebrovascular events associated with patent foramen ovale, atrial septal aneurysm, or both. N Engl J Med 2001; 345: 1740-6.

[39] Schuchlenz HW, Weihs W, Horner S, Quehenberger F. The association between the diameter of a patent foramen ovale and the risk of embolic cerebrovascular events. Am J Med 2000; 109: 456-62.

[40] Anzola GP, Zavarize P, Morandi E, Rozzini L, Parrinello G. Transcranial Doppler and risk of recurrence in patients with stroke and patent foramen ovale. Eur J Neurol 2003; 10: 129-35.

[41] Pezzini A, Del Zotto E, Magoni M, et al. Inherited thrombophilic disorders in young adults with ischemic stroke and patent foramen ovale. Stroke 2003; 34: 28-33

[42] Nendaz MR, Sarasin FP, Junod AF, Bogousslavsky J. Preventing stroke recurrence in patients with patent foramen ovale: antithrombotic therapy, foramen closure, or therapeutic abstention? A decision analytic perspective. Am Heart J 1998; 135: 532-41.

[43] Devuyst G, Despland PA, Bogousslavsky J, Jeanrenaud X. Complementarity of contrast transcranial Doppler and contrast transesophageal echocardiography for the detection of patent foramen ovale in stroke patients. Eur Neurol 1997; 38: 21-5

[44] Homma S, Di Tullio MR, Sacco RL, Sciacca RR, Smith C, Mohr JP. Surgical closure of patent foramen ovale in cryptogenic stroke patients. Stroke 1997; 28: 2376-81.
[45] Devuyst G, Bogousslavsky J, Ruchat P, et al. Prognosis after stroke followed by surgical closure of patent foramen ovale: a prospective follow-up study with brain MRI and simultaneous transesophageal and transcranial Doppler ultrasound. Neurology 1996; 47: 1162-6.

[46] Benbassat J, Baumal R. Variability in duration of follow up may bias the conclusions of cohort studies of patients with patent foramen ovale. Eur J Neurol 2008; 15: 909-15.

[47] Desai AJ, Fuller CJ, Jesurum JT, Reisman M. Patent foramen ovale and cerebrovascular diseases. Nat Clin Pract 2006; 3: 446-55.

[48] Salem DN, O'Gara PT, Madias C, Pauker SG. Valvular and structural heart disease: American College of Chest Physicians Evidence-Based Clinical Practice Guidelines (8th Edition). Chest 2008; 133: 593S-629S

[49] Brown JM, O'Brien SM, Wu C, Sikora JA, Griffith BP, Gammie JS. Isolated aortic valve replacement in North America comprising 108,687 patients in 10 years: changes in risks, valve types, and outcomes in the Society of Thoracic Surgeons National Database. J Thorac Cardiovasc Surg 2009; 137: 82-90.

[50] Cannegieter SC, Rosendaal FR, Briet E. Thromboembolic and bleeding complications in patients with mechanical heart valve prostheses. Circulation 1994; 89: 635-41.

[51] Ad N, Barnett SD, Speir AM, Massimiano PS. Institutional and national trends in isolated mitral valve surgery over the past decade. Curr Opin Cardiol 2008; 23: 99-104.

[52] Vongpatanasin W, Hillis LD, Lange RA. Prosthetic heart valves. N Engl J Med 1996; 335: 407-16.

[53] Geiser T, Sturzenegger M, Genewein U, Haeberli A, Beer JH. Mechanisms of cerebrovascular events as assessed by procoagulant activity, cerebral microemboli, and platelet microparticles in patients with prosthetic heart valves. Stroke 1998; 29: 1770-7.

[54] Tanne D, Reicher-Reiss H, Boyko V, Behar S. Stroke risk after anterior wall acute myocardial infarction. SPRINT Study Group. Secondary prevention reinfarction israeli nifedipine trial. Am J Cardiol 1995; 76: 825-6.

[55] Mooe T, Eriksson P, Stegmayr B. Ischemic stroke after acute myocardial infarction: a population-based study. Stroke 1997; 28: 7627.

[56] Anticoagulants in the Secondary Prevention of Events in Coronary Thrombosis (ASPECT) Research Group. Effect of long-term oral anticoagulant treatment on mortality and cardiovascular morbidity after myocardial infarction. Lancet 1994; 343: 499-503.

[57] Bornstein N, Corea F, Galllai V, Parnetti L. Heart-brain relationship: atrial fibrillation and stroke. Clin Exp Hypertens 2002 ; 24(78): 493-9.

[58] Mattioli AV, Castellani ET, Fusco A, Paolillo C, Mattioli G. Stroke in paced patients with sick sinus syndrome: relevance of atrial mechanical function, pacing mode and clinical characteristics. Cardiology 1997; 88(3): 264-70.

[59] Corea F, Spinelli M, Tambasco N, Silvestrelli G, Parnetti L. Secondary prevention of cardioembolic stroke: oldest and newest promises. Clin Exp Hypertens 2006; 28(3-4): 413-20.

[60] Corea F, Tambasco N. Cardiac pacing: atrial fibrillation may go unrecognised. Lancet Neurol 2005; 4(5): 265.

(C) Giacalone et al.; Licensee Bentham Open.

This is an open access article licensed under the terms of the Creative Commons Attribution Non-Commercial License (http://creativecommons.org/licenses/by-nc/3.0/) which permits unrestricted, non-commercial use, distribution and reproduction in any medium, provided the work is properly cited. 